\title{
Arbor
}

\section{La Percepción Pública de la Ciencia: un ensayo histórico}

\section{Enrique Battaner Arias}

Arbor CLXXIII, 683-684 (Noviembre-Diciembre 2002), 617-635 pp.

\section{Introducción ${ }^{1}$}

La Ciencia y su corolario la Técnica (o quizá al contrario) han modificado profundamente la vida del hombre, y en general, en un sentido de indiscutible progreso. Sin embargo, la sociedad humana, a cuyo beneficio estaría dedicada en principio la Ciencia, no percibe a ésta como una fuente inagotable de bendiciones. A lo largo de la historia, la percepción pública de la ciencia se ha movido entre dos polos opuestos, que para simplificar llamaremos inicialmente percepción positiva y percepción negativa. La primera es la que tiene en cuenta los enormes beneficios que de su práctica se han derivado, y por tanto, desea por encima de todo seguir el camino marcado por ella. La negativa, por el contrario, pone énfasis en sus consecuencias indeseables, que también las hay. Por término medio, una de las dos percepciones predomina en cada época histórica. No hay mejor ejemplo que la comparación entre los dos últimos siglos. Al enorme entusiasmo generado por la Ciencia en el siglo XIX ha seguido en la segunda mitad del XX una creciente desconfianza, y ésta es la percepción común en este siglo XXI que ahora iniciamos.

La percepción negativa de la Ciencia tiene entre el público un hondo significado histórico, que podemos rastrear hasta los orígenes, y que toma esencialmente la forma del Mito de la Edad de Oro. Por su parte, la percepción positiva de la Ciencia se origina en el mito paralelo, inevitable, tan antiguo como aquél, que es el Mito de la Caída. Más o menos pueden enunciarse así: Los benevolentes dioses colocaron al hombre en un estado de pureza prístina, sin necesidades 
ni anhelos, la Edad de Oro. Contento con su destino original, tomaba de la Naturaleza lo que ésta le daba. Pero en un momento dado, el hombre pecó; quiso ser como los dioses, conocer como los dioses, e influir en la Naturaleza como hacen los dioses, lo que condujo a su Caída.

En estos dos mitos paralelos encontraremos la clave de la percepción pública de la Ciencia. Por una parte, la propia de los hombres de la Caída, empeñados en un conocimiento y en un progreso ilimitado, en un dominio total de la Naturaleza. Esta voluntad da origen a la percepción positiva de la Ciencia, que pasa a ser considerada como la fuerza que impulsa a la Humanidad a un destino prácticamente divino, libre de las cargas que su propio ser biológico le impone, desde la enfermedad hasta la muerte. Pero este empeño conlleva sus problemas. La Naturaleza es algo extremadamente grande e impredecible, y toda acción humana encuentra su respuesta natural, que muchas veces no es, ni mucho menos, la que el propio hombre desea.

Por esa razón, el hombre también tiene la percepción de que existió una Edad de Oro, en la que la armonía con la Naturaleza, y no el dominio de la misma, era el valor supremo. Consciente de su pérdida, trata por todos los medios de remedar en lo posible el estado original. Este es el origen de la percepción negativa de la Ciencia, la percepción que trata de poner freno a la ilimitada ambición del hombre de la Caída, culpable de nybris ${ }^{2}$, arrogancia ante los dioses. Por eso la $\mathrm{Hu}-$ manidad a veces recuerda el estado originario, sin preocupaciones, sin necesidades, sin voluntad: la Edad de Oro. Y la recuerda con nostalgia. A veces, incluso, la recuerda con violencia.

\section{La Edad de Oro}

El mito de la Edad de Oro nos habla de una edad idílica, en la que el alimento estaba ahí y el hombre no tenía más que recogerlo; en la que no había guerras, leyes ni castigos; no existía la ambición, la violencia ni la propiedad; no se aventuraba el hombre por vericuetos filosóficos; no había necesidad de moral. La sencillez en la vida y la simplicidad en las relaciones humanas eran la norma. No se edificaba, no se inventaba, pues no había necesidad de ello. Muchas culturas (aunque no todas), recuerdan con nostalgia la Edad de Oro.

En realidad, la Edad de Oro es el recuerdo colectivo que tenemos de la era que llamamos Paleolítico. Nos cuenta el antropólogo Marvin Harris ${ }^{3}$ que el hombre del Paleolítico, cazador-recolector, no tendría 
que trabajar más de unas dos horas semanales para mantenerse óptimamente alimentado. Si comparamos estas dos horas con la llamada «vida moderna» comprenderemos la relatividad de conceptos como "progreso». Pero en realidad la cuestión no es ésa. La Caída que nos sacó de la Edad de Oro no es el Progreso, sino el deseo de progreso; la aspiración, en suma, a ser como dioses.

Para las personas de habla española, nada como esa especie de hispánica biblia que es el Quijote para conocer la Edad de Oro. Don Quijote, tras su lance con el vizcaíno, encuentra cobijo entre unos cabreros, cuya rústica mesa comparten caballero y escudero de muy buen grado. Una vez saciado, Don Quijote tomó unas bellotas y contemplándolas, se embarcó en uno de sus más bellos discursos; ése que empieza por

Dichosa edad y siglos dichosos aquellos a quien los antiguos pusieron nombre de dorados, $y$ no porque en ellos el oro (que en nuestra edad de hierro tanto se estima) se alcanzase en aquella venturosa sin fatiga alguna, sino porque entonces los que ella vivian ignoraban estas dos palabras de tuyo y mío.

La Edad áurea cervantina comienza, pues, por la negación de la propiedad. A continuación, y sucesivamente, trata de la comunidad y abundancia de bienes, lo superfluo de la técnica y del trabajo, la integración del hombre con la Naturaleza, la desnudez no vergonzante, la sencillez de comportamientos, la falta de maldad e iniquidad humanas y lo innecesario de jueces ni leyes; para terminar, cómo no, con la necesidad de la Andante Caballería en esta nuestra desdichada Edad de Hierro. De una forma $u$ otra, estas características aparecen en todas las descripciones de la Edad de Oro. Las fuentes de Cervantes eran, sin duda, los clásicos latinos y griegos. Hesíodo, por ejemplo, recoge el mito en sus Trabajos y Días y Ovidio en sus Metamorfosis.

Pero nuestra cultura es bicéfala. Su tradición semítica es tan importante como la grecolatina. El Génesis no entra en demasiados detalles en cuanto a las bendiciones de la Edad de Oro (el jardín del Edén), sino que, un tanto característicamente, prefiere recrearse en las consecuencias de su pérdida, según veremos.

Como ya adelanté, podemos fácilmente asimilar la Edad de Oro a lo que llamamos el Paleolítico ${ }^{4}$. Se trataba de una sociedad de cazadores-recolectores, cuya actividad era más que suficiente para mantener las necesidades de grupos humanos reducidos, conocedores del fuego, de ciertos instrumentos y de las actividades de caza en grupo. Eran hombres y mujeres no ligados a la tierra, cuyas necesidades 
técnicas eran mínimas. Su carácter nómada excluía todo tipo de territorialidad. La organización social era asimismo primitiva, aunque hemos de suponer al hombre paleolítico una espiritualidad muy bien desarrollada. Nadie que haya contemplado la cueva de Altamira se atrevería a poner en duda ese impulso espiritual y estético de la supuesta Edad de Oro.

La percepción negativa de la Ciencia es, en gran parte, el reflejo del mito de la Edad de Oro, los buenos y viejos tiempos en los que el hombre aceptaba un destino marcado únicamente por imperativos biológicos, y en los que no existía un interés específico en el dominio de la Naturaleza. Ésta daba y quitaba. Pero la Edad de Oro terminó, según sus nostálgicos, por la propia maldad del hombre, que quiso igualarse a los dioses. A falta de mejor nombre, llamaremos Caída al fin de la Edad de Oro.

\section{La Caída}

Alguien debió darse cuenta en algún momento de que la recolección sería más fácil si las plantas comestibles crecieran al lado de su vivienda, y que comer carne animal era factible sin necesidad de moverse de su asentamiento con una cierta domesticación de los animales. Una y otra cosa requiriei on un invento crucial: La Selección Artificial de especies; por ejemplo, cereales de mayor producción, y animales más gregarios y pacíficos ${ }^{5}$. Por vez primera el hombre se atreve a influir en la Naturaleza, modificando lo que ésta ha producido, en un sentido beneficioso para él. La Selección Artificial es un método de ensayo y error; por tanto, la Revolución Neolítica es realmente la invención del método científico. Pero la Técnica es asimismo la Caída, la expulsión del Paraíso. A una población escasa y dispersa sucede una explosión demográfica y la invención de las ciudades; al nomadismo sucede la territorialidad y la posesión de la tierra; al trabajo esporádico, deportivo e incluso reputadamente noble, de la caza, suceden la explotación y el esclavismo. Al igual que surgen las clases poseedoras, con la técnica aparecen las castas sacerdotales, originariamente depositarias de la misma. La propiedad, el trabajo, la explotación, la desigualdad, no dejan de ser consecuencias de la Técnica. Las desagradables consecuencias de querer ser como los dioses.

Nos brinda el Génesis ${ }^{6}$ las claves más sutiles y exactas en la descripción de la Caída. En primer lugar, la definición de la prueba a que el hombre es sometido, en la que no se ofrece el Árbol del 
Placer, o de la Abundancia, o de la Felicidad, sino el árbol de la Ciencia del Bien y del Mal. El Árbol del Conocimiento, de la Técnica, de la Ciencia a la que pueden darse múltiples usos, buenos y malos. Ser como dioses; comprender, dominar y crear; he aquí la alternativa que plantea la serpiente. Éste es el origen de la percepción positiva de la Ciencia, la Ciencia liberadora que nos hace transcender de nuestros más bien modestos límites biológicos.

Con la Caída el hombre optó por su propio destino, escapándose quizá a un determinismo biológico al que quedaron abocados sus parientes evolutivos más próximos. El hombre ha puesto el pie en la Luna. Aunque cuando contempla la miseria que todavía le rodea aquí abajo, no deja de pensar, nostálgicamente, en la Edad de Oro. Y es que la percepción pública de la Ciencia siempre ha sido ambivalente; y me atrevo a decir que siempre lo será. En todos los momentos de la historia, el enfrentamiento dialéctico entre la Edad de Oro y la Caída protagoniza la percepción pública de la Ciencia.

Nos corresponde ahora hablar de los dos protagonistas de la percepción pública de la Ciencia: el Público y el Científico.

\section{El Público y el Científico}

En la historia de ' $a$ filosofía occidental ${ }^{7}$, podemos decir que fueron Pitágoras y Sócrates quienes abrieron una importante brecha entre la Ciencia y el Público. Debemos a los pitagóricos el término «esotérico», relativo a todo aquello que debe ser mantenido secreto, al alcance exclusivo de una minoría ilustrada e iniciada. En cuanto a Sócrates, vemos cómo en los diálogos platónicos contrapone constantemente el Filósofo al hombre vulgar. Con él aparece en escena uno de los personajes protagonistas de esta historia: el Vulgo, la masa supuestamente zafia y grosera, que no merece esas bendiciones que brinda el Saber cultivado por el placer de cultivarlo. Pero desde el punto de vista del Vulgo, que por muy vulgar que sea también tiene opinión, surge el concepto del intelectual pedante, del parásito ocioso, altivo y estirado con que muchas veces se ha mirado - y se mira - a los hombres de Ciencia, y que ha sido fuente inagotable de inspiración para dramaturgos desde Aristófanes hasta Jardiel Poncela pasando por Molière.

Encontramos un ejemplo delicioso en «Las Nubes» de Aristófanes ${ }^{8}$. Fustiga aquí el comediógrafo las pretensiones de una nueva educación y una nueva ciencia promovidas, entre otros, por Sócrates en la Atenas de finales del siglo V antes de Cristo. En esta obra, Estrepsíades, un 
campesino ateniense, trata de buscar métodos dialécticos con los que confundir a sus acreedores. Para ello acude a una supuesta escuela montada por Sócrates, que él llama, burlonamente, «El Pensadero». En un determinado momento, se produce un diálogo muy ilustrativo entre Estrepsíades y Sócrates, sobre la naturaleza de la lluvia. Estrepsíades, por su parte, piensa que la envía Zeus. Sócrates, por la suya, esboza una explicación que hoy llamaríamos «racional» pero que la pluma de Aristófanes convierte en paródica. Frente a las viejas y buenas creencias que mantiene Estrepsíades, Sócrates plantea una explicación desprovista de dioses, en un tono y con unos términos que acentúan ante el espectador su supuesta impiedad. Lo llamativo del caso es que la explicación que da Sócrates es una explicación científica, en el sentido de rechazar toda causalidad sobrenatural en los fenómenos naturales. Pero Aristófanes sabe dar al público de Atenas lo que éste le pide: la mofa y escarnio público del sabelotodo que se cree por encima de los venerables dioses y las no menos venerables tradiciones, e incluso pretende crear escuela teniendo discípulos. Sócrates es la Caída; Estrepsíades, la Edad de Oro, recordada con nostalgia por el comediógrafo. Sócrates es el atrevido, aquél cuya hybris nos lleva a la perdición; y que como tal, fue condenado a muerte por el demos de Atenas en el 399 a. J.C. Los argumentos de sus acusadores nos suenan hoy día, a comienzos del siglo XXI, harto familiares. El impío cuya enseñanza hizo escarnio de los dioses, provocando así la humillante derrota en la Guerra del Peloponeso, no deja de parecerse al codicioso sistema productivo que alterando los buenos usos alimenticios de los animales domésticos termina llevándonos al mal de las vacas locas.

Dando un salto importante en el tiempo que nos lleve al siglo XXI, el problema de las relaciones públicas de la ciencia sigue en pie, aunque con nuevos condicionantes. El Vulgo ya no es tal; se ha transformado en El Público; y no se crea que esto es una concesión a la fastidiosa corrección política en el lenguaje que nos abruma. El Público no es lo mismo que el Vulgo de otros tiempos. Está escolarizado y mucho mejor informado que el Vulgo; hoy día, lo está, prácticamente, en tiempo real. Dado el intenso grado de especialización en el conocimiento, el propio científico se convierte en Público cuando se le saca de su parcela concreta de saber.

En la transformación de Vulgo en Público han tenido y tienen un papel determinante los medios de comunicación. Para los cínicos, el Público no es más que la Humanidad moldeada a los intereses de los medios y sometida a sus designios. No lo creo yo así, sin embargo. 
El Público y los medios son dos realidades interdependientes. $\mathrm{Ni}$ el Público hubiera llegado a ser tal sin los medios ni éstos existirían de no haber Público. La realimentación entre uno y otros es continua. $\mathrm{Y}$ el asunto que nos ocupa, la percepción pública de la Ciencia, es hoy día consecuencia, más que nunca, de esta interrelación.

Veamos ahora el polo opuesto de esta historia: el hombre de Ciencia, el hombre de la Caída.

El hombre productor de Ciencia no ha sido siempre el mismo en la historia. La Ciencia y la técnica estuvieron originariamente en manos de sacerdotes, y en este sentido, Grecia y Roma fueron una excepción. El filósofo antiguo era por lo general un ciudadano acomodado, ocioso y posiblemente explotador de esclavos. Este arquetipo persistió, con pocas variaciones, durante la Antigüedad Clásica. Con la caída del mundo antiguo, la Ciencia pasa nuevamente al estamento sacerdotal. En el occidente europeo, la Iglesia y sus hombres fueron los depositarios de la Ciencia hasta bien entrado el siglo XVI. Pero la revolución humanista y la Reforma hacen que la ciencia vuelva nuevamente a cambiar de manos. El filósofo urbano, cuya pista habíamos perdido en la Antigüedad, vuelve a surgir en el siglo XVII: de hecho, la Revolución Científica fue protagonizada por «Filósofos», tanto en Inglaterra como en el Continente Europeo. El Filósofo fue el último generalista. Con la Revolución Industrial, surge en la Ciencia la especialización, protagonizada por una nueva figura, la del Sabio.

El Sabio decimonónico es una especie de santo laico. Protagonista de las mejoras y del progreso que el público constata por doquier, lleva una vida austera, dedicada a la Verdad, en contraste con el carácter altivo y algo pedante del Philosophe diociochesco. Por vez primera, el Sabio pasa a la categoría de héroe popular; y las «hazañas» del Sabio se difunden y son admiradas por un público entusiasmado, proceso concomitante con el nacimiento de los medios de comunicación de masas. La Percepción Pública de la Ciencia llega así en el siglo XIX a su particular Edad de Oro. Pero con la vuelta del siglo, la imagen del Sabio tenía los días contados. El siglo XX ha visto una nueva metamorfosis: la del Sabio en Científico. Al tiempo, como veremos, el Científico pierde el rostro.

Siempre me ha llamado la atención el hecho de que los científicos del siglo XIX y del primer XX son mucho más conocidos que nuestros contemporáneos, independientemente de la calidad de su trabajo, y a pesar de vivir, como vivimos, en la era de la comunicación. $Y$ es que a partir de las guerras del siglo XX, y particularmente desde la Segunda, 
el científico ha perdido el rostro. La «guerra científica» hizo su aparición en la Primera Guerra Mundial, como parte indispensable de la llamada «guerra total» ${ }^{9}$. El uso generalizado de armas químicas por parte de los beligerantes supone la entrada, por vez primera en la historia, del laboratorio en el campo de batalla. Y en ese sentido, el estallido de la Segunda Guerra Mundial no tomó por sorpresa a los beligerantes. Desde el primer momento la Ciencia fue considerada como un importantísimo protagonista del esfuerzo bélico.

La expresión máxima de esta tendencia, y la que trascendió al Público por razones obvias, fue el proyecto Manhattan ${ }^{10}$. El gobierno de los Estados Unidos reunió una inmensa concentración de inteligencia en el laboratorio de Los Álamos para producir la primera bomba nuclear. El éxito científico de dicho proyecto crea conceptos nuevos en la producción de ciencia: Uno es el equipo y su líder; otro, compartimentación y seguridad. A partir de entonces, la ciencia como aventura individual prácticamente desaparece, siendo sustituída por la ciencia en equipo. Al tiempo, la libre comunicación de ideas pasa a la historia en aras de la seguridad. El Público, desde fuera, no ve más que la alambrada que rodea a un complejo ingente de laboratorios y talleres.

El proyecto Manhattan supuso, a mi entender, un punto de inflexión en la consideración pública de la Ciencia. Al optimismo positivista del XIX, a la fe ilimitada en los avances de la ciencia, sucede una visión de laboratorios secretos al servicio del Poder, más preocupado de su propia pervivencia que del bienestar de los ciudadanos. Más aún; en las postrimerías del siglo XX, en plena borrachera neoliberal, el público contempla al laboratorio como un ámbito de generación de enormes beneficios para las compañías multinacionales que lo sostienen, habiendo perdido el carácter casi evangélico que llegó a tener en el XIX.

Una tendencia preocupante en el ámbito científico es la pérdida progresiva del carácter público de su financiación. Los éxitos relativos frente al SIDA han sido, en su gran mayoría, protagonizados por compañías privadas. La compañía Celera Genomics dio un solemne aldabonazo al anunciar, en la primavera del 2000, la resolución de la secuencia completa del Genoma Humano ${ }^{11}$. Todo esto no hace sino añadir nuevos componentes a la percepción negativa de la Ciencia. El científico anónimo, miembro de un equipo de dedicación absoluta a la Empresa, ha llegado a sustituir ante los ojos del Público al Sabio austero, humilde, laborioso y dedicado absolutamente a la Verdad que fue durante el siglo XIX. 


\section{La percepción pública de la Ciencia en el siglo XXI}

Vivimos en un momento singular, debido más que nada a la impresionante revolución habida en el ámbito de la comunicación y de la información. No me refiero sólo al fenómeno Internet, cuyo análisis es difícil debido a su propia juventud y que en materia de percepción pública de la Ciencia es, paradójicamente, un medio más propenso a la Edad de Oro que a la Caída. Me refiero también a esa información en tiempo real a la que estamos sometidos, desde la inmediatez de la radio o del teléfono móvil hasta el práctico sometimiento de la cultura al todopoderoso medio televisivo.

Todo ello hace que la percepción pública de la Ciencia esté en gran parte modelada por los medios de comunicación, aunque en el sentido que apunté más arriba: la relación entre el Público y los medios es recíproca. Esta percepción se manifiesta en una serie de formas de las que trataremos a continuación, y que sin ninguna intención de exhaustividad, serán las siguientes: Iconos científicos, publicidad, ecologismo, percepción lúdica de la Ciencia y crisis científicas.

\section{i. Iconos científicos}

La influencia de los medios de comunicación y la cultura visual lleva a una imagen de la ciencia en gran parte hecha de iconos. Tomo este término por su significado original, el de imagen sacra. Un icono es algo más que la mera imagen representada. Hay detrás todo un significado, sacro o profano, que se nos transmite a modo de mensaje. En la percepción pública de la Ciencia el icono es hoy día tan importante como en la' percepción pública del hecho religioso. El icono, por otra parte, no es neutro; nos mueve a la veneración o a la abominación. Hay iconos materiales, como el modelo planetario del átomo o la doble hélice del ADN; pero mucho mayor interés tienen los iconos personales en la percepción actual de la Ciencia.

No hay duda de que, por ejemplo, la percepción pública actual de la Cosmología está en gran parte ligada a la imagen de Stephen Hawking, el cosmólogo aquejado de una esclerosis lateral amiotrófica que ha reducido su movilidad al manejo de un ordenador hecho a medida a través del cual se comunica ${ }^{12}$. Que una persona inválida, hablando a través de un sintetizador de voz, sea el gran profeta de la distorsión del tiempo, de los agujeros negros y otras exóticas criaturas del bestiario cósmico, no deja de ser llamativo en un contexto en el que el culto 
al cuerpo perfecto y a la juventud forman parte asimismo de la imaginería del gran público. No se trata, desde luego, de un sentimiento compasivo o admirativo el que mueve al espectador; no se trata tanto de valorar la derrota de la minusvalía ante el poder intelectual como de poner etiquetas de exotismo a todo lo que rodea a Hawking. La Cosmología es una rama particularmente exótica de la Ciencia: masas y energías extremas; tiempos asintóticos, alfas y omegas. De ahí el éxito de la imagen de Hawking, tan ajeno a las imágenes humanas convencionales.

En la percepción pública actual de la Ciencian hay asimismo otros iconos personales. Gran importancia tuvo a principios del siglo XX el de madame Curie; tanta como la que hoy tiene Albert Einstein ${ }^{13}$, indiscutible icono científico de nuestros tiempos. El rostro de Albert Einstein se ha convertido en un objeto de consumo, en un icono representativo del siglo XX, del mismo modo que la imagen del Che Guevara.

Es la Física, sin duda, la que mayor cantidad de iconos personales ha producido ante el gran público. Lo cual no deja de ser curioso, puesto que ciencias como la Biología y la Medicina deberían lógicamente estar más cercanas a su percepción. Sólo en la época de las grandes generalizaciones, el siglo XIX, y en un país con la tradición caricaturesca y científica de Inglaterra, podemos encontrar imágenes de Darwin como soporte de su teoría. El rostro algo adusto de Charles Darwin combinaba perfectamente con todo tipo de cuerpos y posturas simiescas ${ }^{14}$. Incidentalmente, en esta nuestra España desgraciadamente tan periférica en lo que a Gran Ciencia se refiere, el icono de Charles Darwin encontró un curioso destino: sigue aún hoy apareciendo en el envase de una bebida reciamente hispánica, cual es el Anís del Mono ${ }^{15}$.

Esta alusión a una marca de fábrica nos vale para introducir el siguiente apartado: la Ciencia en la publicidad.

\section{La percepción seudocientífica en la publicidad}

Los términos científicos se han convertido en un aditamento imprescindible de los mensajes publicitarios, particularmente en los terrenos de la alimentación, de la salud y de la cosmética. A veces el mensaje se hace particularmente abstruso. Vemos, por ejemplo, productos lácteos que anuncian ostensiblemente pertenecer a la serie $\omega$-3. Esto tiene un significado bioquímico bien claro (para el bioquímico, se entiende). Se trata de la presencia en el producto anunciado de ácidos grasos con una insaturación en el tercer carbono empezando 


\section{La Percepción Pública de la Ciencia: un ensayo histórico}

a contar desde el último (que convencionalmente se llama carbono $\omega$ ). Podemos apreciar así cómo se hace un mensaje publicitario con un concepto que podría estar al alcance de un estudiante de Bioquímica General, pero no, en absoluto, del gran público. No obstante, ahí queda; y lo que es más importante, puede en el futuro crear demanda. Días llegarán en que solicitemos una docena de huevos $\omega-3$.

Otro ejemplo, tomado éste de la cosmética, es un mensaje publicitario en el cual las excelencias de un determinado producto de belleza se ensalzaban diciendo que contenía «ADN marino». Las siglas ADN (de ácido desoxirribonucleico) están tomando valor icónico, en el sentido que veíamos antes, ante los espectaculares y recientes avances de la genómica. Bástenos decir que se trata del material genético, la sustancia que determina todas nuestras características heredadas, desde el hecho de tener dos manos hasta el color de los ojos. ¿Qué puede significar entonces «ADN marino»? La imagen publicitaria que se pretende comunicar es, sin lugar a dudas, sugestiva de brisas templadas, playas de cocoteros, cuerpos sanos y bronceados, ocio y diversión. Pero ADN marino sólo puede ser $\mathrm{ADN}$ de seres que viven en el mar. $\mathrm{Y}$ dado que el $\mathrm{ADN}$ es el material genético, la presencia de $\mathrm{ADN}$ «marino» en nuestro organismo podría conducir, en un escenario de ficción científica fundamentada, a nuestra propia transformación en una espectacular medusa.

Pero la percepción pública de la ciencia en la publicidad no solamente camina a través de conceptos científicos o seudocientíficos. La tendencia denunciada antes sobre la desconfianza creciente de la sociedad ante la Ciencia, nostalgia, una vez más, de la Edad de Oro, se traduce muy frecuentemente en contenidos claramente anticientíficos en los mensajes que se reciben. A ello ha contribuído, sin lugar a dudas, la preocupación actual sobre el medio ambiente, y que, con cierta sutileza semántica, llamamos «ecologista» en lugar de lo que hubiera sido normal, que no es otra que «ecológica». En efecto: mensajes como «sin colorantes ni conservantes» se toman como características deseables de un determinado producto, y como tales, se anuncian. El producto supuestamente «natural», desprovisto de tecnología y más cercano a la Edad de Oro, toma ventaja sobre otros más manipulados por la mano de la industria.

\section{El movimiento ecologista}

Ninguna tendencia actual nos aproxima más al mito de la Edad de Oro que el ecologismo radical y militante de nuestros días. Ya men- 
cioné anteriormente la sutileza que hacemos al distinguir «Ecologismo» de «Ecología». El sufijo «ismo» implica tendencia, y en este caso, militancia. No faltan razones para el Ecologismo, ni mucho menos. La Naturaleza aborrece los procesos de crecimiento exponencial. Pero el hombre de la Caída, el que aspira a dios, no es persona dada a realimentaciones ni frenos; y por vez primera en la Historia, estamos asistiendo a un peligro real que se cierne sobre el planeta en su conjunto debido a la propia actividad del hombre. Existen amenazas reales sobre el medio ambiente, y lejos de mi ánimo trivializarlas o minimizarlas.

En la percepción pública de la Ciencia el pensamiento ecologista está tomando un considerable arraigo. A ello han ayudado, cómo no, los medios de comunicación. Las populares series de documentales sobre la Naturaleza que se han sucedido ocupando incluso franjas de audiencia máxima, y de la mano de hábiles divulgadores, han creado una cierta demanda pública de atención al medio ambiente y una estima pública de las ciencias de campo que no encontramos en otras ramas del saber. Pero esto no se traduce en una percepción positiva de la Ciencia en el sentido definido más arriba. Las alusiones a la limpieza primigenia de los ríos, la belleza de los campos de antaño, o los bosques frondosos de nuestra infancia tristemente sustituídos por una urbanización, nos llevan derechos a la nostalgia de la Edad de Oro. Y es en ese caldo donde la variante radical del ecologismo medra de la forma más espectacular. Con raíces utópicas y libertarias, esta tendencia de nuestros días parte de una percepción francamente negativa de la Ciencia, que a veces llega a ser acrítica cuando no pura y simplemente disparatada ${ }^{16}$.

Muchas consideraciones ecologistas han pasado a ser parte integrante de la percepción pública de la Ciencia, sobre todo cuando constatamos el actual predominio de la percepción negativa, de la cual el pensamiento ecologista es realmente un componente importantísimo. Pero no se vea en mis palabras una crítica contra el ecologismo sin más. Mi intención ha sido simplemente colocarlo, en su variante radical, como paradigma del mito de la Edad de Oro en la actualidad. El pensamiento ecologista ${ }^{17}$ ha logrado forzar el tratado de la Antártida, nos ayuda a establecer los niveles de $\mathrm{CO}_{2}$ permisibles en la atmósfera y suministra las bases sobre una política global de protección del planeta; bienvenido sea, pues. El progreso siempre ha de hacerse como lucha de contrarios, como realimentaciones recíprocas de tendencias opuestas. Si hay excesos en el ecologismo, también los hay, y de qué magnitud, en la parte contraria. 


\section{La Percepción Pública de la Ciencia: un ensayo histórico}

\section{La percepción lúdica de la Ciencia}

La omnipresencia de los medios de comunicación y de la llamada industria del entretenimiento han hecho que la Ciencia haya cobrado entre el Público una nueva dimensión, que vamos a llamar lúdica, y que a veces llega a constituir un fenómeno de masas. El hecho científico se presenta como ingrediente central de una trama de ficción. No faltan, en la ficción científica, las dos percepciones básicas de la Ciencia. Ray Bradbury, por ejemplo, nos remite a la Edad de Oro; mientras que otros, como Arthur C. Clarke toman definitivamente partido por la Caída y sus consecuencias. Así, a nadie extraña hoy día que el ordenador central de control de una nave espacial pueda volverse loco, como ocurre con HAL en 2001, una odisea espacial; viajar a velocidades superiores a la luz (lo cual es físicamente imposible) es la cosa más natural del mundo en la Guerra de las Galaxias; y vivir entre voraces velocirraptores es el destino de los héroes de Parque Jurásico. La Ciencia contribuye de esta manera a elaborar un mundo de fantasía, de evasión, sin que falten, explícitas o implícitas, moralejas que corresponden a las percepciones clásicas de la misma, y mayoritariamente en el campo de la nostalgia por la Edad de Oro. El Público acepta alegremente esta percepción lúdica del avance científico, pero a costa de un cierto descrédito de la Ciencia.

A modo de ejemplo, podemos citar una serie televisiva de las llamadas «de culto». No es otra que «Expediente $X$ », en la que dos agentes del FBI, famoso uno de ellos por su declarada heterodoxia ante las explicaciones racionales, se dedican a desvelar misterios que el Poder, por razones inconfesables, parece empeñado en ocultar de manera enfermiza. Como señala el evolucionista y divulgador Richard Dawkins ${ }^{18}$, y cito literalmente,

Cada semana Expediente $X$ plantea un misterio y ofrece dos explicaciones, la científica y la paranormal. Sin variación posible, es esta última la que siempre gana, para descrédito de la científica. Imaginen ahora una serie policíaca en la que cada semana los agentes encuentran dos sospechosos, uno negro y otro blanco. ¿Qué pensaríamos si cada semana se demostrara que el culpable real era indefectiblemente el negro?

Esto no puede ser despachado simplemente diciendo que se trata de ficción y que no tiene mayor importancia. Hay definitivamente un sesgo anticientífico en la actual percepción lúdica de la Ciencia. El Público goza con el escarnio de la supuestamente todopoderosa Ciencia, máxime cuando ha salido del cálido ámbito del Sabio y ha pasado a 
ser patrimonio de un Científico venalmente entregado al Poder y a las multinacionales.

\section{Las crisis cientificas}

Con el nombre de crisis científicas entiendo el conjunto de situaciones que se producen ante un problema social de índole sanitaria, técnica o económica que surge inesperadamente y que coexiste con una percepción por parte del público, errónea o no, de que la ciencia puede resolverlo. En las crisis científicas hay, además, otros componentes. $\mathrm{Al}$ haber surgido de forma inesperada, no suele haber respuestas científicas claras; al no haberlas, entran en juego deformaciones espontáneas, y también, desgraciadamente, deformaciones deliberadas de la realidad científica. He tomado como ejemplos de crisis científicas actuales la pandemia de SIDA y las encefalopatías espongiformes.

La aparición en 1982 del Síndrome de Inmunodeficiencia Adquirida o SIDA ${ }^{19}$ ha dado lugar a una crisis científica en la que los elementos que hemos esbozado en la percepción pública de la Ciencia aparecen plasmados en toda su magnitud. Para empezar, se trata de una enfermedad infecciosa, que incide sobre una Humanidad a la que desde la Ciencia se había dicho que las enfermedades infecciosas eran cosa del pasado. Y efectivamente: el triunfo sobre dichas enfermedades es quizá el hecho que más ha contribuído a una percepción positiva de la ciencia en el siglo XX. De repente, surge una nueva epidemia contra la cual no se dispone de nada: ni vacunas ni quimioterapia. La primera reacción del Público, en gran medida, fue la de esperar al remedio, que no debería tardar, según la lógica científica del siglo $\mathrm{XX}$ sobre las infecciones. Pero no fue así. El virus causante del SIDA daba la impresión de conocer previamente todos nuestros trucos terapéuticos, a los que se escapaba una y otra vez.

Al tiempo, la epidemia se presentó con unas características que impactaron hondamente en su percepción pública. Los primeros casos fueron descritos en homosexuales masculinos, aunque no tardó en descubrirse su transmisión heterosexual. Para una sociedad que había pasado por la revolución sexual de los '60 y de los '70, promovida por los métodos anticonceptivos y por la solución antibiótica a las enfermedades de transmisión sexual clásicas, la epidemia de SIDA supuso un aldabonazo no ya sólo a la percepción pública de las enfermedades infecciosas, sino a toda una revolución social que había tenido lugar en las sociedades avanzadas. La epidemia, desde sus pri- 


\section{La Percepción Pública de la Ciencia: un ensayo histórico}

meros momentos, tomó el carácter siniestro de azote infeccioso a colectivos marginales. Las preguntas del público ante la pandemia de SIDA eran ¿Por qué no hacen nada? ¿Por qué no tenemos ya resuelto este problema, como se resolvieron la viruela, la peste bubónica y la poliomielitis? ¿Qué intereses inconfesables hay detrás de todas estas demoras? ¿A quién puede beneficiar esta epidemia?

Ante todo ello, la percepción pública del problema tiende inexorablemente hacia el lado negativo. La Ciencia, en su soberbia, es incapaz de dar con un remedio, lo cual da lugar a las especulaciones más extravagantes sobre su origen. La afectación de colectivos de vida digamos heterodoxa hace el resto; y las viejas atribuciones al castigo divino por nuestros pecados hacen su aparición en las postrimerías del siglo XX. Se castiga la conducta heterodoxa y se castiga, al tiempo, la soberbia y la hybris de los hombres de la Caída, de los científicos que pretenden emular a Dios. Volvemos, una vez más, a la nostalgia de la Edad de Oro. Hay páginas en Internet dedicadas al SIDA que podrían muy bien haber sido firmadas por los flagelantes medievales que surgieron con ocasión de la Peste Negra en 1348.

La reacción de la Ciencia ante la pandemia de SIDA ha sido sintomática de los derroteros por los que camina en los tiempos actuales. No estamos ya en la época del Sabio decimonónico; quien ha trabajado en el remedio contra el SIDA es el Científico; y no ya el Científico, sino el equipo de científicos hasta cierto punto anónimos, y característicamente, al servicio de compañías multinacionales ${ }^{20}$, que no dudan en invertir grandes recursos sabedoras de los enormes beneficios que pueden obtener a cambio. La percepción negativa de la Ciencia se apunta otro tanto: el hombre de la Caída no sólo pretende emular a Dios; incluso se ha vendido al Demonio.

A mediados de los años ochenta apareció en Inglaterra una nueva enfermedad en el ganado bovino, la llamada encefalopatía espongiforme bovina o, más comúnmente, mal de las vacas locas ${ }^{21}$. Relacionada desde el principio con una enfermedad del ganado ovino conocida como scrapie desde nada menos que el siglo XVIII, le fueron encontrados asimismo vínculos con la patología humana, como el kuru o la enfermedad de Creutzfeld-Jakob. Pronto la epizootia alcanzó proporciones catastróficas en Inglaterra. Las encuestas epidemiológicas señalaron rápidamente que el origen del mal podría estar relacionado con las harinas animales empleadas en la alimentación del ganado. Tras las inevitables guerras comerciales y consabidos embargos pareció que las aguas volvían a su cauce. 
Pero bajo la superficie, y lejos de los medios de comunicación, tenía lugar un desarrollo científico revolucionario. El agente causal de la enfermedad no era un organismo vivo, pero tampoco era un virus; se trataba de un nuevo tipo de agente, propuesto en los años 70 , y que fue llamado prion como acrónimo de partícula proteica infecciosa. A pesar de haber dado lugar a la concesión de dos premios Nobel, el concepto se salía de la Biología Molecular canónica y era contemplado con escepticismo por la comunidad científica.

A finales de la década de los 90, estalla la crisis. En Inglaterra primero, y en Francia y Alemania después, aparece una nueva enfermedad espongiforme humana, parecida a la de Creutzfeld-Jakob, pero afectando a personas mucho más jóvenes. Y entonces los acontecimientos se precipitan. A pesar de unos índices estadísticos más bien modestos, con un número muy limitado de casos en relación a la posible causa - el consumo de carne supuestamente infectadaestalla ante el Público una crisis científica de primera magnitud.

La percepción pública de todos estos hechos cae sin ninguna duda dentro del campo de lo que hemos llamado nostalgia de la Edad de Oro, en mayor medida si cabe que en el caso del SIDA. Ante nosotros se nos presenta todo un escándalo promovido por los hombre de la Caída, cuya soberbia y avaricia han convertido en carnívoros, y no solo carnívoros, sino caníbales de sus propios despojos, a unos pacíficos herbívoros que antes veíamos pastando por los campos. El lamentable espectáculo de los gallineros industriales en los que una cinta transportadora introduce a los pollos jóvenes, otra saca a los muertos, otra introduce piensos debidamente hormonados y una cuarta y principal canaliza el torrente de huevos producidos, resulta que también se aplica, mutatis mutandis, al ganado bovino, cuya condición de camarada mamífero debería al menos ser tenida en cuenta. No es ya la Edad de Oro, sino la actividad del pacífico ganadero Abel la que se ve escarnecida por un espectáculo más propio del agricultor Caín. La enfermedad humana resultante es lo mínimo con lo que se puede castigar tanta codicia y tanta srobervia; tanta hybris, en suma.

A todo esto, la Ciencia está realmente perpleja y recibe constantes interrogaciones por parte de un Público poco menos que enfurecido. ¿Qué me " " ' infeccioso, transmisible y a la vez hereditaria, restringida a una especie pero transmisible entre especies, cuyo diagnóstico más fidedigno sólo puede tener lugar post mortem y que por añadidura es incurable? ¿Es ésta la manera de gastar dineros públicos? Por supuesto, el resto de los ingredientes de las crisis científicas modernas han aparecido 


\section{La Percepción Pública de la Ciencia: un ensayo histórico}

en todo su esplendor. La encefalopatía se convierte en bandera política; un bando hace público escarnio de la ministra de Sanidad y del ministro de Agricultura; y desde el otro bando se nos afirma con toda seriedad que el problema era anterior a 1996.

Pero al tiempo, se aprovecha para rejuvenecer la cabaña bovina por el expeditivo procedimiento del sacrificio de las reses más viejas; la política agraria europea se ve libre de abonar un sustancioso paquete de subvenciones, y lo más notable de todo, el problema desaparece de los medios de comunicación tan súbitamente como empezó. En la opinión pública, el conjunto de los acontecimientos que han acompañado a esta crisis parece o bien una escalada de despropósitos o bien un plan maquiavélico urdido desde el Poder con no se sabe muy bien qué objeto. Lo cual no contribuye, ciertamente, a una percepción positiva de la Ciencia.

\section{Conclusión}

La percepción pública de la Ciencia es en la actualidad un conjunto de actitudes ambivalentes. Por una parte, se aceptan sus logros y se confía, en términos generales, en sus métodos. Una formación científica se considera credencial válida, cuando no necesaria, para entrar en el sistema productivo. Pero al mismo tiempo existe una desconfianza creciente hacia ese mismo sistema, y en la medida en que la Ciencia está definitivamente a su servicio, hacia la propia Ciencia.

Por otra parte, se cierne a principios del siglo XXI un gran peligro sobre la Ciencia: el alarmante auge de los fundamentalismos. La raíz de los fundamentalismos está, hoy por hoy, en las desigualdades flagrantes a que dan lugar las actuales relaciones económicas internacionales. La conciencia colectiva de quienes las sufren culpa a la codicia desmesurada de los países ricos y sus multinacionales; o a aquéllos que quieren llegar a dioses sin respeto por los demás; a los hombres, en suma, de la Caída. Para ello reivindican sus particulares Edades de Oro, en las que el hombre no se apartaba de los designios de su Creador. Desde quienes se manifiestan violentamente contra la globalización, os productos transgénicos, las reuniones del Fondo Monetario Internacional y las del G-8, hasta quienes en Estados Unidos, por enésima vez, prescriben la enseñanza obligatoria del relato bíblico de la Creación en la enseñanza de las Ciencias Naturales, pasando por los flagelantes medievales y los acusadores de Sócrates, hay un continuo de percepción negativa de la Ciencia y de nostalgia de la 
Edad de Oro. Pero también hay cierto fundamentalismo en el campo contrario, y particularmente en la Ciencia instrumental, la Ciencia al servicio de los poderes establecidos.

¿Adónde puede llegar la Ciencia? No hay respuesta clara. Puede llevarnos incluso más allá del límite marcado por la imaginación humana. No obstante, la Ciencia es amiga de establecer límites y barreras. La incertidumbre en lo infinitamente pequeño; la limitación marcada por la velocidad de la luz; la cantidad de información que puede almacenar un sistema; la flecha termodinámica del tiempo; la irreversibilidad de la mayoría de los procesos biológicos; el intervalo de vida de la Tierra, del Sol o de la Galaxia. Con el tiempo, la Humanidad llegará a estos límites; veremos qué dirá la Ciencia entonces. Puede decirnos que no hay más remedio que la vuelta a la Edad de Oro, $\mathrm{y}$ que el intento de ser como dioses fue vano. Pero también puede llegar a demostrar que la serpiente, la que nos empujó a la Caída, allá en el Edén, estaba en lo cierto.

\section{Notas}

1 El presente trabajo es un resumen de la lección inaugural de curso pronunciada por el autor el día 28 de Septiembre de 2001, bajo el título «La Percepción Pública de la Ciencia» en la Universidad de Salamanca.

2 Ver JAEGER (1974); FLÓREZ MIGUEL (1994).

3 HARRIS (1982).

4 Muchos estudiosos del Paleolítico sostienen, incluso con pasión, esta equivalencia. Ver RAMOS MUÑOZ (1999), p. 373.

5 COHEN (1981).

6 Gén 2, 16-17; Gén 3, 4-6, 22.

7 RUSSELL (1981).

8 El texto Nubes 365-85, fue amablemente traducido por el Prof. Antonio López Eire a instancias del autor.

9 FERRO (1984).

10 JUNGK (1970).

$11 \mathrm{El}$ anuncio fue hecho por R.Craig Venter en Abril de 2000 ante el Subcomité de Energía de la Cámara de Representantes de los Estados Unidos.

12 McEVOY et al. (1995).

13 BRIAN (1997).

14 ELLE $\because A R D$ y HULL (1990)

15 Ver http://www.fortunecity.es/felices/barcelona/31/licores.html Se da por hecho que el rostro del mono es el de Charles Darwin. Sin embargo, la familia Bosch, propietaria original de la marca, no lo cree así, tal como tuve ocasión de comprobar en la amable respuesta de la empresa a la consulta que a tal efecto envié. refood.

16 Ver p.e. la página $h t t p: / / w w w$.purefood.org/text.html de la organización $\mathrm{Pu}-$ 


\section{La Percepción Pública de la Ciencia: un ensayo histórico}

17 La página de la organización Greenpeace, $h t t p: / / w w w . g r e e n p e a c e . o r g ~ m u e s t r a$ los frentes actuales del movimiento ecologista.

18 Citado por G. PRYCE y M. EVENING, New Scientist, February 1997.

19 STEPHENSON (2001).

20 Por ejemplo: Glaxo Wellcome, Bristol Myers-Squibb, Hoffmann-La Roche, Abbott Laboratories, Merck \& Co., Boehringer Ingelheim, Agouron, Pharmacia \& Upjohn, DuPont Pharmaceuticals.

21 Ver LACEY (1995) y MAURER y SOBAL (1995).

\section{Bibliografía}

Cervantes Saavedra, M. de. (1993) El Ingenioso Hidalgo don Quijote de la Mancha.. Austral.

Clarke, A.C. (1968) 2001: A Space Odissey. Polaris.

Cohen, M.N. (1981) La crisis alimentaria de la Prehistoria. Alianza Universidad.

Crichton, M. (1992) Parque Jurásico. Plaza y Janés.

Ellegard, A; Hull, D.L. (1990) Darwin and the General Reader: the Reception of Darwins Theory od Evolution in the British Periodical Press, 1859-1872. University of Chicago Press.

Ferro, M. (1984) La Gran Guerra (1914-1918) Alianza Universidad.

Flórez Miguel, C. (1994) Mundo Técnico y Humanismo. Ed.Universidad de Salamanca. Harris, M. (1982) El Materialismo Cultural. Alianza Universidad.

Hesfodo (2000) Trabajos y Días (trad. y ed. A.Martín Sánchez y MT.Martín Sánchez) Alianza Editorial.

Agger, W. (1974) Paideia: Los ideales de la cultura griega. Fondo de Cultura Económica Jungk, R. (1970) Brighter than a Thousand Suns. Penguin Books.

LACEY, R.W. (1995) Making an Issue of Food Safety. The media pressure groups and the public sphere. Ipsela Press, New Jersey.

LuCAS, G. (1978) Star Wars: From the Adventures of Luke Skywalker. Ballantine Books. Maurer, D.; SOBAL, J. (1995) Food Eating and Nutrition as Social Problems: constructivist perspectives. Aldine de Gruyter.

Mcevoy, J.P; Zarate, S.; Appignanesi, S; Hawking, S. (1995) Introducing Stephen Hawking. Totem Books.

Publio Ovidio Nasón (1997). Las Metamorfosis (trad. y ed.Consuelo Álvarez y Rosa $\mathrm{M}^{\mathrm{a}}$ Iglesias). Cátedra.

Ramos MuÑoz, J. (1999) Europa Prehistórica: Cazadores y recolectores. Silex.

Russell, B.(1961) History of Western Philosophy. Allen \& Unwin.

StEPHENSON, J. (2001) 20 years after AIDS emerges, HIV's complexities still loom large. JAMA Medical News and Perspectives, March. 